\title{
RESEARCH
}

Open Access

\section{Comparison of two ASC-derived therapeutics in an in vitro OA model: secretome versus extracellular vesicles}

Chiara Giannasi ${ }^{1{ }^{*}} \mathbb{D}$, Stefania Niada ${ }^{1 \dagger}$, Cinzia Magagnotti ${ }^{2}$, Enrico Ragni ${ }^{3}$, Annapaola Andolfo $^{2}$ and Anna Teresa Brini ${ }^{1,4}$

\begin{abstract}
Background: In the last years, several clinical trials have proved the safety and efficacy of adipose-derived stem/ stromal cells (ASC) in contrasting osteoarthritis (OA). Since ASC act mainly through paracrine mechanisms, their secretome (conditioned medium, CM) represents a promising therapeutic alternative. ASC-CM is a complex cocktail of proteins, nucleic acids, and lipids released as soluble factors and/or conveyed into extracellular vesicles (EV). Here, we investigate its therapeutic potential in an in vitro model of OA.

Methods: Human articular chondrocytes $(\mathrm{CH})$ were induced towards an OA phenotype by $10 \mathrm{ng} / \mathrm{ml}$ TNFa in the presence of either ASC-CM or EV, both deriving from $5 \times 10^{5}$ cells, to evaluate the effect on hypertrophic, catabolic, and inflammatory markers.

Results: Given the same number of donor cells, our data reveal a higher therapeutic potential of ASC-CM compared to EV alone that was confirmed by its enrichment in chondroprotective factors among which TIMP-1 and -2 stand out. In details, only ASC-CM significantly decreased MMP activity (22\% and 29\% after 3 and 6 days) and PGE2 expression (up to $40 \%$ at day 6) boosted by the inflammatory cytokine. Conversely, both treatments down-modulated of $\sim 30 \%$ the hypertrophic marker COL10A1.
\end{abstract}

Conclusions: These biological and molecular evidences of ASC-CM beneficial action on $\mathrm{CH}$ with an induced OA phenotype may lay the basis for its future clinical translation as a cell-free therapeutic in the management of OA.

Keywords: Adipose-derived stem/stromal cells, Secretome, Extracellular vesicles, Chondrocytes, Osteoarthritis, Hypertrophy, MMP, PGE2

\footnotetext{
* Correspondence: chiara.giannasi@grupposandonato.it

${ }^{\dagger}$ Chiara Giannasi and Stefania Niada contributed equally to this work.

'Laboratorio di Applicazioni Biotecnologiche, IRCCS Istituto Ortopedico Galeazzi, Milan, Italy

Full list of author information is available at the end of the article
}

(c) The Author(s). 2020 Open Access This article is licensed under a Creative Commons Attribution 4.0 International License, which permits use, sharing, adaptation, distribution and reproduction in any medium or format, as long as you give appropriate credit to the original author(s) and the source, provide a link to the Creative Commons licence, and indicate if changes were made. The images or other third party material in this article are included in the article's Creative Commons licence, unless indicated otherwise in a credit line to the material. If material is not included in the article's Creative Commons licence and your intended use is not permitted by statutory regulation or exceeds the permitted use, you will need to obtain permission directly from the copyright holder. To view a copy of this licence, visit http://creativecommons.org/licenses/by/4.0/ The Creative Commons Public Domain Dedication waiver (http://creativecommons.org/publicdomain/zero/1.0/) applies to the data made available in this article, unless otherwise stated in a credit line to the data. 


\section{Background}

Osteoarthritis (OA) is an age-related disease that affects millions of people worldwide, representing a leading cause of locomotor disability and therefore entailing high socio-economic costs [1]. Its pathogenesis is complex and engages different tissues. However, despite the proved involvement of subchondral bone and synovium during the degenerative process, the impairment of both the structure and the function of articular cartilage is still recognized as one of the earliest disease causing events [2, 3].

Currently, OA cannot be reversed pharmacologically, but treatments can help relieve its symptoms. The medications most commonly used in OA treatment are intraarticular corticosteroids, topical and oral non-steroidal anti-inflammatory drugs (NSAID), duloxetine, and acetaminophen, often accompanied by physiotherapy and life style modification $[4,5]$. In the worst cases, when conservative approaches fail, arthroplasty remains the only option. Although the available treatments improve the quality of life in OA patients by reducing pain and promoting joint mobility, the need to achieve adequate tissue regeneration and to develop drugs able to modify the course of the disease (disease-modifying anti-OA drugs, DMOAD) is still unmet. In this context, orthobiologics are emerging as alternative therapeutic tools, thanks to their regenerative potential and costeffectiveness [6, 7]. These approaches include intraarticular injection of platelet-rich plasma (PRP) and biografts, such as autologous chondrocyte implantation (ACI), bone marrow concentrate (BMC), and adiposederived stem/stromal cell (ASC) therapy. The latter techniques rely on the presence, in both bone marrow and fat, of progenitor cells called mesenchymal stem/ stromal cells (MSC). In response to various stimuli, MSC can differentiate into specialized cell types and/or behave as "signaling" cells, able to pour into the microenvironment several mediators, such as nucleic acids, proteins, and lipids, that orchestrate the regenerative process by modulating the immune system and recruiting specialized effectors (e.g., mast cells and T lymphocytes). In the last years, in vitro [8-10] and in vivo [1113] studies have proved the therapeutic potential of MSC in counteracting cartilage damage and, to date, more than 100 clinical trials have evaluated/are assessing the safety and efficacy of MSC intra-articular injection in OA patients (http://www.clinicaltrials.gov). Since nowadays it is widely accepted that MSC action is largely mediated by paracrine mechanisms [14], the scientific interest has shifted towards the study of their secretome, the conditioned medium (MSC-CM). Indeed, cell secretome is a cocktail of soluble factors and extracellular vesicles $(\mathrm{EV})$ with a promising potential in regenerative applications. EV are particles naturally released from the cell that are delimited by a lipid bilayer and may be of both endosomal origin or plasma membrane-derived [15]. Since a consensus has not emerged on specific markers of EV subtypes yet, the recent nomenclature established by the International Society for Extracellular Vesicles (ISEV) divides EV into small $(<200 \mathrm{~nm})$ and large $(>200 \mathrm{~nm})$ particles, previously called exosomes and microvesicles based on their endosomal or plasma membrane origin [16]. Two works have recently reviewed the available evidence of MSC-CM therapeutic action on cartilage, subchondral bone and synovium [17, 18]. Among other MSC sources, adipose tissue presents several advantages in terms of harvesting procedure, cell isolation, and expansion [19]. ASC efficacy and safety have been largely studied, both in vitro and in vivo, and confirmed by clinical trials [20, 21]. Moreover, ASC therapy in the treatment of COVID-19 disease has recently shown promising outcomes [22, 23]. In recent years, our group investigated and characterized ASCCM content in terms of both soluble factors [24] and vesicular components [25, 26]. Furthermore, we evaluated ASC-CM effects in vitro on a model of human articular chondrocytes $(\mathrm{CH})$ induced towards an OA-like phenotype by the inflammatory cytokine TNF $\alpha$ [27]. In our previous study, we proved that ASC-CM contains high levels of chondroprotective factors and exerts short-term anti-hypertrophic and anti-catabolic effects on TNF $\alpha$-treated $\mathrm{CH}$, confirming the potential of this cell-free approach in the management of OA. The present work aims at disclosing which components of ASC secretome play the major role in its beneficial action, by comparing the effects of ASC-CM and ASC-EV deriving from $5 \times 10^{5}$ cells in the same OA in vitro model.

\section{Methods}

Unless otherwise stated, reagents were purchased from Sigma-Aldrich, St. Louis, MO, USA.

\section{Cell cultures}

Cell cultures were obtained from waste tissues collected at IRCCS Istituto Ortopedico Galeazzi upon Institutional Review Board approval. Written informed consent was obtained from all donors. In detail, ASC (1 male and 3 females; $43 \pm 15$ years old) and $\mathrm{CH}$ ( 4 males and 3 females, $64 \pm 13$ years old) were isolated from patients undergoing esthetic or prosthetic surgery, following well-established protocols [24, 27, 28]. Briefly, after mechanical fragmentation of the subcutaneous adipose tissue deriving from abdominoplasty surgery $(n=3)$ or abdominal liposuction $(n=1)$, ASC were isolated by enzymatic digestion with $0.75 \mathrm{mg} / \mathrm{ml}$ type I Collagenase (Worthington Biochemical Corporation, Lakewood, NJ, USA) for $30 \mathrm{~min}$ and filtering of the stromal vascular 
fraction through a 100- $\mu \mathrm{m}$ cell strainer (Corning Incorporated, Corning, NY, USA) [29]. All ASC donors were normal-weight subjects $(\mathrm{BMI}<30$, no documented diagnosis of obesity). $\mathrm{CH}$ derived from the femoral head of OA patients who underwent total hip replacement: only the areas of macroscopically healthy cartilage (white, shiny, elastic, and firm) were harvested through a scalpel and digested overnight at $37^{\circ} \mathrm{C}$ with $1.5 \mathrm{mg} / \mathrm{ml}$ type II Collagenase (Worthington Biochemical Corporation, Lakewood, NJ, USA) $[28,30]$. The areas characterized by irregular surface, discoloration or softening were never collected, even at the cost of losing the entire sample, in order to exclude any experimental bias linked to the use of strongly compromised cartilage. Cells were cultured in high glucose DMEM supplemented with 10\% FBS (Euroclone, Pero, Italy), $2 \mathrm{mM} \mathrm{L-glutamine,} 50 \mathrm{U} / \mathrm{ml}$ penicillin, and $50 \mu \mathrm{g} / \mathrm{ml}$ streptomycin at $37^{\circ} \mathrm{C}$ in a humidified atmosphere with $5 \% \mathrm{CO}_{2}$. The culture medium was further implemented with $110 \mu \mathrm{g} / \mathrm{ml}$ sodium pyruvate for $\mathrm{CH}$ maintenance. Prior serum starvation for $\mathrm{CM}$ and EV production, ASC were characterized as previously described [31-34] and their features are summarized in Supplementary Table 1.

\section{$\mathrm{CM}$ and $\mathrm{EV}$ production}

Conditioned medium was collected from $\sim 90 \%$ confluent ASC (IV to VI passage) cultured for $72 \mathrm{~h}$ under starving conditions (absence of FBS), following optimized procedures [24]. Cells were monitored every day. No signs of cell suffering (e.g., detaching) was ever observed and cell viability was maintained for the whole starving duration (data not shown), consistently with a recent report by Petrenko et al. [35] After $72 \mathrm{~h}$, conditioned media were collected and centrifuged at $2500 \times g$ for $15 \mathrm{~min}$ at $4{ }^{\circ} \mathrm{C}$ to remove dead cells, large apoptotic bodies, and debris. The supernatants were split in half to obtain coupled CM and EV samples, while donor cells were counted in order to correlate cell number to the appropriate treatment volumes. An aliquot of conditioned medium was centrifuged for $90 \mathrm{~min}$ at $4000 \times g$, $4{ }^{\circ} \mathrm{C}$, inside Amicon Ultra-15 Centrifugal Filter Devices with 3-kDa cut-off (Merck Millipore, Burlington, MA, USA), resulting in a 40-50-fold more concentrated final product. This procedure leads to a final product whose safety and efficacy have been already shown both in vitro [27] and in vivo [36]. In parallel, EV isolation was performed starting from naïve conditioned medium through differential centrifugation at $100,000 \times g, 4{ }^{\circ} \mathrm{C}$ [25]. Both final products were characterized as follows.

\section{Secretome characterization}

\section{Nanoparticle tracking analysis (NTA)}

Coupled ASC-CM and ASC-EV samples were appropriately diluted in $0.22 \mu \mathrm{m}$ triple-filtered PBS and analyzed by NanoSight NS300 (Malvern PANalytical, Salisbury, UK). For each measurement, 3 videos lasting 1 min were captured. All measurements matched the quality criteria of 20-120 particles/frame, concentration of $10^{6}-4 \times 10^{9}$ particles $/ \mathrm{ml}$ and valid tracks $>20 \%$. Upon capture, videos were analyzed by the in-build NanoSight Software NTA.

\section{Cytofluorimetry}

Prior to cytofluorimetry analysis, ASC-CM and ASC-EV were appropriately diluted in $0.22 \mu \mathrm{m}$ triple-filtered $\mathrm{PBS}$ and stained with the green fluorescent dye CFSE (carboxyfluorescein diacetate succinimidyl ester). In details, ASC-derived products were incubated with $20 \mathrm{nM}$ CFSE for $1 \mathrm{~h}$ at $37^{\circ} \mathrm{C}$ [37], then analyzed without any further washing. All data were obtained using a CytoFLEX flow cytometer (Beckman Coulter, Brea, CA, USA). At first, instrument calibration was set using Megamix-Plus SSC (Biocytex, Marseille, France), a reference bead mixture composed of FITC fluorescent spheres of heterogeneous dimensions $(160 \mathrm{~nm}, 200 \mathrm{~nm}, 240 \mathrm{~nm}$, and $500 \mathrm{~nm})$. CFSE-positive $\left(\mathrm{CFSE}^{+}\right.$) ASC-CM was run to set in SSC$\mathrm{H}$ and FITC-H channels the region where to expect our events, accordingly to the coordinates given by the standardization beads (Fig. 1b). $\mathrm{CFSE}^{+}$samples were then incubated for $20 \mathrm{~min}$ at $4{ }^{\circ} \mathrm{C}$ in the dark with APCconjugated antibodies raised against $\mathrm{CD} 9, \mathrm{CD} 63$, and CD81 (BioLegend, San Diego, CA, USA, dilution 1:20) EV markers, as per well-documented protocols and general ISEV guidelines for positive EV characterization [16, 38], then 1:2 diluted in $0.22 \mu \mathrm{m}$ triple-filtered PBS and acquired for $300 \mathrm{~s}$ at a low flow rate [39]. PBS-diluted antibodies and unlabeled samples were used as appropriate controls.

\section{Transmission electron microscopy}

PBS-resuspended EV were absorbed for 10 min on Formvar carbon-coated grids, and excess liquid was removed by a filter paper. Two percent uranyl acetate solution was used as negative stain for $10 \mathrm{~min}$ and excess of liquid was removed by a filter paper. The grid was dried at room temperature. Eventually, absorbed EV were examined with a TALOS L120C transmission electron microscope (Thermo Fisher Scientific, Waltham, MA, USA) at $120 \mathrm{kV}$.

\section{Western blotting of secretome samples}

For CM and EV samples, protein concentration was determined using Bio-Rad Protein Assay (Bio-Rad, Milan, Italy) following standard procedures. ASC-CM and -EV samples presented a total protein concentration of $0.49 \pm 0.27$ and $0.11 \pm 0.04 \mu \mathrm{g} / \mu \mathrm{l}$, respectively. For Western Blot analyses, specimens were lysed in Laemli buffer and analyzed as exhaustively described in $[25,26]$. 

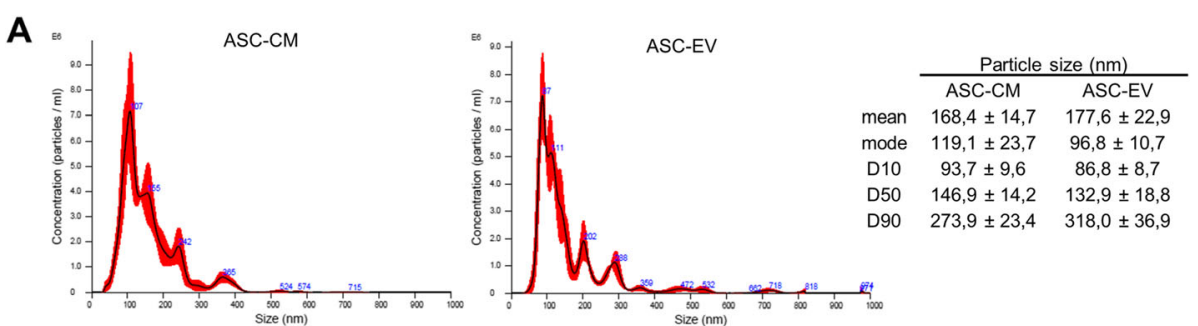

B

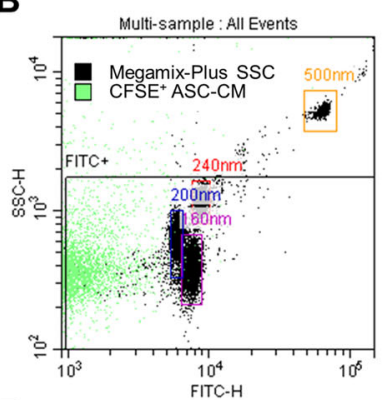

E

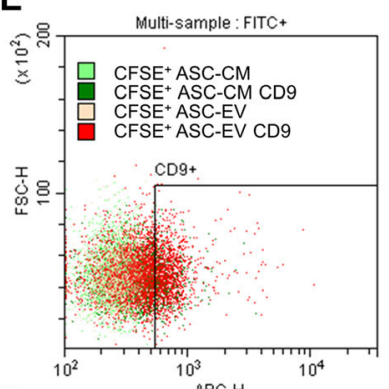

H

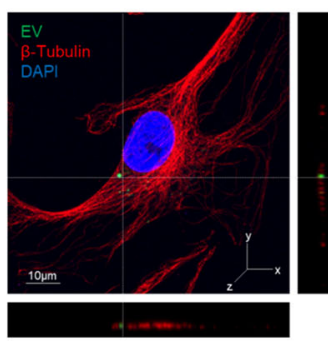

C

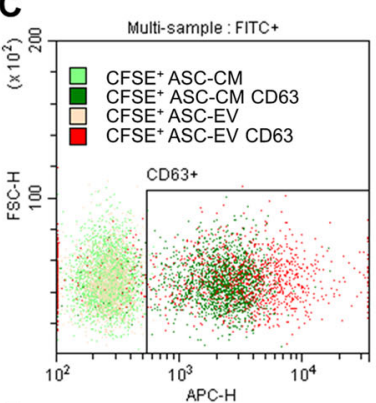

$\mathbf{F}$

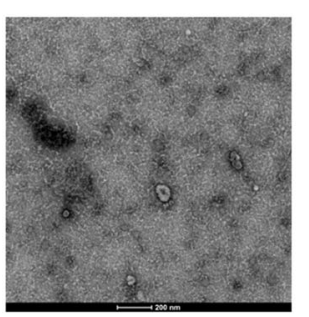

I

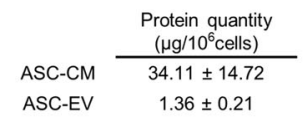

D

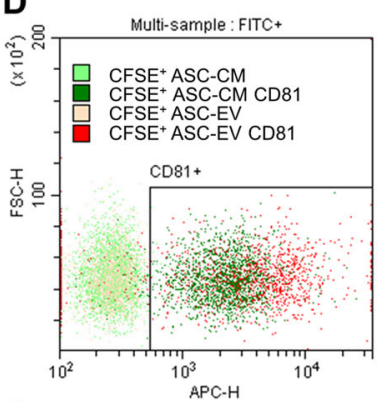

G

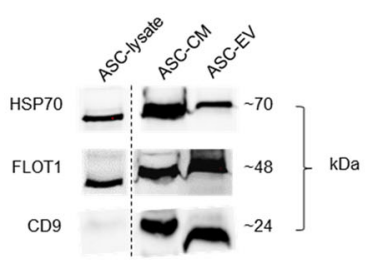

$\mathbf{L}$

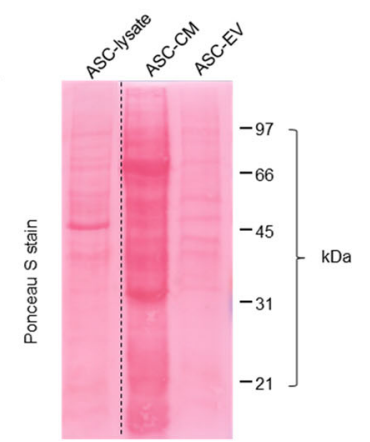

Fig. 1 Characterization of ASC-CM and -EV. a Representative images of NTA referred to ASC-CM (left) and ASC-EV (right). The table shows the dimensional parameters of the samples expressed as mean \pm SD of 6 NTA measurements. $\mathbf{b}$ Flow cytometer calibration with standard beads and $\mathrm{CFSE}^{+}$ASC-CM. The FITC ${ }^{+}$gate encloses the coordinates in SSC-H and FITC-H channels where to expect the events of interest. c-e CD63, CD81, and CD9 staining of representative CFSE ${ }^{+}$ASC-CM and ASC-EV samples. $\mathbf{f}$ Transmission electron microscopy image showing the characteristic morphology of EV. The scale bar indicates $200 \mathrm{~nm}$. g Representative Western blot of ASC-CM and EV lysates deriving from $10^{6}$ ASC. Cell lysate from $5 \times 10^{4} \mathrm{ASC}$ is shown as control. $\mathbf{h}$ Laser scanning confocal microscopy of $\mathrm{CH}$ treated with ASC ${ }^{\mathrm{GFP}+}{ }_{-} \mathrm{EV}$ for 3 days. $\beta$-Tubulin was revealed with an Alexa Fluor 568 conjugated antibody (red), nuclei were stained with DAPI (blue) (magnification $\times 63$ ). The scale bar indicates $10 \mu m$ and the orthogonal views were obtained by Fiji software. $\mathbf{i}$ Total protein content per million ASC $\left(\mu \mathrm{g} / 10^{6}\right.$ cells). Data are shown as mean \pm SD $(n=4)$. I Ponceau S staining of ASC-CM and -EV lysates from $10^{6}$ ASC. Cell lysate from $5 \times 10^{4}$ ASC is also shown

Briefly, proteins from CM and EV lysates deriving from $10^{6} \mathrm{ASC}$ (respectively 34.1 and $1.4 \mu \mathrm{g}$ for ASC-CM and -EV) were resolved into $12 \%$ SDS-PAGE, transferred onto a nitrocellulose membrane, stained for $1 \mathrm{~min}$ with Ponceau $\mathrm{S}$, and then probed for the expression of the typical EV markers HSP70 (ExoAb, System Biosciences,
Palo Alto, CA, USA, dilution 1:1000), FLOT1 (BD Biosciences, San Jose, CA, $250 \mu \mathrm{g} / \mathrm{ml}, 1: 500$ diluted), and CD9 (ExoAb, System Biosciences, Palo Alto, CA, USA, dilution 1:1000) [16, 40]. Specific signals were revealed after incubation with appropriate secondary antibodies (Mouse IgG Secondary Antibody, Thermo Fisher 
Scientific, Waltham, MA, USA, $1.5 \mu \mathrm{g} / \mu \mathrm{l}, 1: 2000$ diluted, or ExoAb Rabbit Secondary Antibody System Biosciences, Palo Alto, CA, USA, dilution 1:20,000), followed by detection with ECL Westar Supernova (Cyanagen, Bologna, Italy). Images were acquired with ChemiDoc Imaging System (Bio-Rad, Milan, Italy).

\section{Confocal laser scanning microscopy}

As a proof of concept of EV internalization in our system, EV deriving from ASC ${ }^{\mathrm{GFP}+}$ [41] (kindly provided by Dr. Giulio Alessandri of IRCCS Neurological Institute Carlo Besta, Milan) were isolated through standard procedures and administered in vitro to $\mathrm{CH}$ seeded on glass coverslips. After 3 days, specimens were fixed in $4 \%$ paraformaldehyde, permeabilized with $0.1 \%$ Triton $\mathrm{X}$ 100 , and incubated overnight at $4{ }^{\circ} \mathrm{C}$ with a monoclonal antibody raised against $\beta$-Tubulin (Sigma-Aldrich, St. Louis, MO, USA, $2 \mathrm{mg} / \mathrm{ml}$, 1:100 diluted). The next day, samples were incubated at room temperature for $45 \mathrm{~min}$ with a goat anti-mouse secondary antibody conjugated with Alexa Fluor 568 (Abcam, Cambridge, UK, 2 mg/ $\mathrm{ml}, 1: 1000$ diluted). After 3 washes, coverslips were then mounted using ProLong ${ }^{\mathrm{TM}}$ Diamond AntifadeMountant with DAPI (Thermo Fisher Scientific, Waltham, MA, USA) and analyzed by the confocal laser scanning microscope TCS SP8 (Leica Microsystems CMS GmbH, Wetzlar, Germany) using a $\times 63$ objective. The obtained images were processed with Las X (Leica Microsystems CMS GmbH, Wetzlar, Germany) and analyzed with Fiji software.

\section{In vitro $O A$ induction and treatments}

In our experimental set up, $\mathrm{CH}$ were always employed at 1st culture passage in order to prevent their dedifferentiation [42]. We clarified this aspect in the text following the reviewer's suggestion. Briefly, $\mathrm{CH}$ were seeded at the density of $10^{4}$ cells $/ \mathrm{cm}^{2}$ in tissue culturetreated 6-well plates (Corning Incorporated, Corning, NY, USA) and cultured in complete medium until the full confluence was reached [43], then shifted in a complete medium containing 1\% FBS, treated with 10 $\mathrm{ng} / \mathrm{ml} \mathrm{TNF} \alpha$ to mimic OA microenvironment [27, 44] and $\mathrm{CM}(38.7 \pm 16 \mu \mathrm{l})$ or $\mathrm{EV}(6.8 \pm 2.2 \mu \mathrm{l})$ from $5 \times 10^{5}$ ASC. OA was induced by TNF $\alpha$ for 3 and 6 days, concurrently with CM or EV treatment. At day 3 or 6 , without any media change, supernatants were collected and cells lysed for further analyses.

\section{Western blotting of $\mathrm{CH}$ samples}

$\mathrm{CH}$ were lysed in $50 \mathrm{mM}$ Tris- $\mathrm{HCl}$ (pH 7.5), $150 \mathrm{mM}$ $\mathrm{NaCl}, 1 \% \mathrm{NP}-40$, and $0.1 \%$ SDS supplemented with protease inhibitor cocktail (PIC) and 2 mM PMSF. Upon incubation on ice for $30 \mathrm{~min}$, lysates were centrifuged for $15 \mathrm{~min}$ at $15,000 \times g, 4{ }^{\circ} \mathrm{C}$, in order to eliminate cell membranes and collect the cytosolic fraction. The protein content of each sample was quantified through BCA Assay (Thermo Fisher Scientific, Waltham, MA, USA). Measurements were performed in technical duplicates. Samples were analyzed by $10 \%$ SDS-PAGE and Western blotting (WB), using standard protocols [27]. For each sample, $10 \mu \mathrm{g}$ of protein extract were loaded and probed with the following primary antibodies: rabbit antiCollagen X (Thermo Fisher Scientific, Waltham, MA, USA, dilution 1:100), mouse anti-MMP13 (Thermo Fisher Scientific, Waltham, MA, USA, 0.4 $\mu \mathrm{g} / \mu \mathrm{l}, 1: 100$ diluted), rabbit anti-MMP3 (Cell Signaling, Danvers, MA, USA, dilution 1:1000), rabbit anti-Connexin 43 (Cell Signaling, Danvers, MA, USA, dilution 1:1000), and goat anti-GAPDH (Santa Cruz Biotechnology, $0.1 \mu \mathrm{g} / \mu \mathrm{l}$, 1:1000 diluted). Specific bands were revealed upon incubation with appropriate secondary antibodies conjugated to horseradish peroxidase (Rabbit IgG Secondary antibody, Thermo Fisher Scientific, Waltham, MA, USA, dilution 1:10,000; Mouse IgG Secondary Antibody, Thermo Fisher Scientific, Waltham, MA, USA, dilution 1:6000; Goat IgG Secondary Antibody, Santa Cruz Biotechnology, CA, USA; 0.1 $\mu \mathrm{g} / \mu \mathrm{l}, 1: 6000$ diluted) followed by detection with ECL Westar Supernova (Cyanagen, Bologna, Italy). After image acquisition with ChemiDoc Imaging System, protein expression was quantified through Image Lab Software (Bio-Rad, Milan, Italy). To normalize target protein expression, the band intensity of each sample was divided by the intensity of the loading control protein GAPDH. Then, the fold change was calculated by dividing the normalized expression from each lane by the normalized expression of the control sample $(\mathrm{CTRL}=1)$.

\section{Analyses of culture supernatants}

$\mathrm{CH}$ culture supernatants were collected and centrifuged for $5 \mathrm{~min}$ at $2000 \times g, 4{ }^{\circ} \mathrm{C}$, to remove dead cells and debris, aliquoted and stored at $-20{ }^{\circ} \mathrm{C}$. MMP activity was assessed with SensoLyte 520 Generic MMP Activity Kit (AnaSpec, Fremont, CA, USA), following the standard protocols. Briefly, pro-enzyme activation was performed through incubation with $1 \mathrm{mM}$ AMPA (4-aminophenylmercuric acetate) for $3 \mathrm{~h}$ at $37^{\circ} \mathrm{C}$ in order to assess simultaneously the activity of different MMP. Measurements were performed in technical duplicates. The length of this incubation was chosen according to the manufacturer's instructions as the preferential activation time to assess the activity of MMP-1 and -3, both strongly involved in OA. Samples were then incubated with the appropriate substrate for $45 \mathrm{~min}$ to run the enzymatic reaction and the resulting fluorescence signal (excitation $\lambda=490 \mathrm{~nm}$, emission $\lambda=520 \mathrm{~nm}$ ) was read with Wallac Victor II (Perkin Elmer, Milan, Italy). ADAMTS4 activity was tested using SensoLyte 520 
Aggrecanase-1 Assay Kit (AnaSpec, Fremont, CA, USA), following standard procedures. PGE2 levels were assessed through Prostaglandin E2 Human Competitive ELISA Kit (Thermo Fisher Scientific, Waltham, MA, USA) following the kit instructions; then, data were analyzed with MyAssays analysis tool (https://www.myassays.com). Measurements were performed in technical duplicates.

\section{nLC-MS/MS of ASC-CM and -EV}

ASC-CM and ASC-EV samples were analyzed by differential proteomics. Twenty micrograms of total proteins from each sample were in-solution digested using filteraided sample preparation (FASP) protocol, as reported in literature [45]. Aliquots of the samples containing tryptic peptides were desalted using StageTip C18 (Thermo Fisher Scientific, Bremen, Germany) and analyzed by $\mathrm{nLC}-\mathrm{MS} / \mathrm{MS}$ using a Q-Exactive mass spectrometer (Thermo Fisher Scientific, Bremen, Germany) equipped with a nano-electrospray ion source (Proxeon Biosystems, Odense, Denmark) and a nUPLC Easy nLC 1000 (Proxeon Biosystems, Odense, Denmark). Peptide separations occurred on a homemade $(75 \mu \mathrm{m}$ i.d., $15 \mathrm{~cm}$ long) reverse phase silica capillary column, packed with 1.9- $\mu \mathrm{m}$ ReproSil-Pur 120 C18-AQ (Dr. Maisch HPLC $\mathrm{GmbH}$, Ammerbuch-Entringen, Germany). A gradient of eluents A (distilled water with $0.1 \% \mathrm{v} / \mathrm{v}$ formic acid) and $B$ (acetonitrile with $0.1 \% \mathrm{v} / \mathrm{v}$ formic acid) was used to achieve separation $(300 \mathrm{~nL} / \mathrm{min}$ flow rate). After 5 min at $2 \%$ of $B$, the acetonitrile phase was increased up to $40 \%$ B in $83 \mathrm{~min}$, followed by a wash step at $90 \%$ of B. Full scan spectra were acquired with the lock-mass option, resolution set to 70,000 and mass range from $\mathrm{m} / \mathrm{z}$ 300 to $2000 \mathrm{Da}$. The ten most intense doubly and triply charged ions were selected and fragmented. All MS/MS samples were analyzed using Mascot (version 2.6, Matrix Science) search engine to search the human_proteome 20190703 (96,470 sequences; 38,319,731 residues). Searches were performed with the following settings: trypsin as proteolytic enzyme, 2 missed cleavages allowed, carbamidomethylation on cysteine as fixed modification, protein $\mathrm{N}$-terminus-acetylation and methionine oxidation as variable modifications, and mass tolerance was set to $5 \mathrm{ppm}$ and to $0.02 \mathrm{Da}$ for precursor and fragment ions, respectively. To quantify proteins, the raw data were loaded into the MaxQuant [46] software version 1.6.1.0. Label-free protein quantification was based on the intensities of precursors. The experiments were performed in technical triplicates. Data are expressed as label-free quantification (LFQ) intensity, count per second (cps). In order to identify differences between ASC-CM and -EV that can be relevant in the OA context, the list of proteins quantified by nLC-MS/ MS was run using the following keywords: Chondro-,
Metabol-, Catabol-, Inflamm-, and Matrix. The keywords were chosen considering that $\mathrm{OA}$ is an inflammatory disease affecting the osteochondral unit and altering extracellular matrix metabolism and catabolism. The functional enriched processes were then identified using STRING (Search Tool for the Retrieval of Interacting Genes/Proteins) (https://string-db.org/). Each identified process is reported in Supplementary Table 2 along with its GO identifier, the number of mapped genes within our dataset, the number of mapped genes in the reference dataset, its $p$ value, and the list of gene names within our dataset. Using the gene names assigned to each of the five selected functional processes and their protein abundance levels measured by nLC-MS/MS, principal component analysis (PCA), and heat maps were obtained using XLSTAT software. To validate nLC-MS/MS data, the presence of selected molecules in ASC secretome was confirmed by immunoassays through the Bio-Plex Multiplex System (Bio-Rad, Milan, Italy). In details, OPG and DKK-1 were quantified with the Human Bone Magnetic Bead Panel-Bone Metabolism Multiplex Assay (HBNMAG-51K, Millipore, Burlington, MA, USA), MMP1 and 2 with the Human MMP Magnetic Bead Panel 2 (HMMP2MAG-55 K, Millipore, Burlington, MA, USA), while TIMP-1,- 2 and -3 with the Human TIMP Magnetic Luminex Performance Assay (LKTM003, R\&D Systems, Minneapolis, MN, USA). Technical duplicates were analyzed for each $\mathrm{CM}$ sample following previously described procedures [27, 47] and data analysis was performed with the MAGPIX xPONENT 4.2 software (Luminex Corporation, Austin, TX, USA). The concentration of the selected molecules is reported in Supplementary Table 3 along with the processes in which each factor is involved, as indicated in Supplementary Table 2.

\section{Statistics}

Statistical analysis was performed by one-way analysis of variance (ANOVA) using Tukey's post hoc test in case of normally distributed measures, otherwise (i.e., PGE2 and COL10A1 data) by Friedman's test followed by Dunn's multiple comparison. Differences were considered significant at $p \leq 0.05$. Unless otherwise stated, data are expressed as mean \pm SD of 5-7 independent experiments. All the analyses were performed using Prism 5 (GraphPad Software, La Jolla, CA, USA).

\section{Results}

\section{ASC-CM and -EV characterization}

NTA demonstrates a comparable size distribution between ASC-CM and ASC-EV samples (Fig. 1a), with the $50 \%$ of events falling inside the dimensional range of $147 \pm 14$ and $133 \pm 19 \mathrm{~nm}$, respectively. Given the same number of donor ASC, the two preparations differ for 
particle concentration, with a post-ultracentrifugation recovery of about $30 \%$ of the input (ASC-CM $=9.0 \pm$ $4.3 \times 10^{8}$ particles $/ 10^{6}$ cells and ASC-EV $=2.6 \pm 0.9 \times 10^{8}$ particles $/ 10^{6}$ cells). Flow cytometry confirms a similar EV size (Fig. 1b) and a comparable expression of vesicular markers (Fig. 1c-e). In details, most of the vesicles are included within $240 \mathrm{~nm}$ (Fig. 1b) and the percentage of positive events for the EV markers CD63 (> 79\%), CD81 (>76\%), and CD9 (> 28\%) is alike in ASC-CM and -EV (Fig. 1c-e). Transmission electron microscopy supported the presence of nanoparticles with the characteristic cup-shaped morphology and the expected size range (Fig. 1f). Furthermore, protein expression of HSP70, Flotillin-1 (FLOT1), and CD9 shows a similar vesicular phenotype (Fig. 1g). ASC-EV were able to interact with recipient cells: indeed in Fig. 1h, as a proof of concept, the incorporation of EV derived by $\mathrm{ASC}^{\mathrm{GFP}+}$ [41] in $\mathrm{CH}$ is shown. The spatial co-localization of the green (EV or $\mathrm{EV}$ cluster from $\mathrm{ASC}^{\mathrm{GFP}+}$ ) and the red (cytoskeleton) signals shown in the orthogonal views suggests the incorporation of vesicular elements in the recipient cell. Additional evidence is provided in Supplementary Figure 1. At last, ASC-CM contains 25-fold more proteins (in terms of quantity) than EV samples, indicating that soluble factors are also abundant (Fig. 1i, l).

\section{ASC-CM, but not ASC-EV, significantly reduces TNFa- induced MMP activity}

Unstimulated $\mathrm{CH}$ secrete low levels of active matrix metalloproteinases (MMP), but their activity is strongly increased by the inflammatory stimulus at both time points $(+2498 \%$ and $+1781 \%$, respectively) (Fig. 2a). ASC-CM significantly reverts TNF $\alpha$-induced activation of about $22 \%$ and $29 \%$ at day 3 and 6 (Fig. 2a, left and right panel, respectively). In contrast, no effect was exerted by the treatment with EV. Differential proteomics allowed the quantification of TIMP-1 and -2, the two most abundant TIMP (tissue inhibitors of MMP) in ASC secretome [24, 27] (Fig. 2b). These data, obtained analyzing the same amount of proteins for ASC-CM and -EV, revealed that both inhibitors are slightly more represented in CM samples (Fig. 2b). Actually, CM contains far more TIMP than EV per ASC number, since EV samples are derived from a 25-fold higher number of cells. The fact that CM acts mainly through the presence of MMP inhibitors is further supported by the lack of effect on MMP expression. Protein expression of MMP-13 and MMP-3, two matrix-degrading enzymes involved in OA [48-50], is displayed in Fig. 2c and d and in Supplementary Figure 2. Despite the large inter-donor variability due to the use of patient-derived articular chondrocytes, a clear effect of TNF $\alpha$ on MMP expression is always present. Differently, CM exerts no effect on their overexpression, as previously shown [27], nor did EV. ADAMTS-4 activity was also tested, since TIMP act also on aggrecanases. However, in our experimental setting, its activity was always undetectable (data not shown).

\section{ASC-CM and ASC-EV differently modulate inflammation and hypertrophy markers in TNFa-treated $\mathrm{CH}$}

In order to investigate $\mathrm{CH}$ activation by $\mathrm{TNF} \alpha$ and an effect of ASC secretome, we examined PGE2 release, total protein content, Collagen $\mathrm{X}$, and Connexin 43 expression. As expected, TNF $\alpha$ raises the extracellular concentration of the inflammatory mediator PGE2, scaling it more than 2 orders of magnitude at both time points (Fig. 3a). Since high PGE2 concentrations can inhibit proteoglycan synthesis and stimulate matrix degradation [51, 52], a possible counteracting effect of ASC secretome was hypothesized. ASC-CM decreased PGE2 upregulation up to $40 \%$ at day 6 (Fig. 3a, right panel). Conversely, ASC-EV did not affect TNF $\alpha$-induced PGE2 levels.

By contrast, both ASC-derived treatments partly blunt TNF $\alpha$ effect (about - 30\%) on the production of Collagen type X (COL10A1, Fig. 3b), a short chain collagen expressed by hypertrophic $\mathrm{CH}$ [50]. EV induced a more long-lasting effect while ASC-CM acted incisively only at the early time point (Fig. 3b, right and left panel, respectively, Supplementary Figure 2).

The TNF $\alpha$-induced phenotypic shift towards hypertrophy can be inferred by the significant increase in $\mathrm{CH}$ total protein content (Fig. 3c, $+38 \%$ ), due to an increase in cell proliferation. ASC-CM did not counteract TNF $\alpha$ induced cell growth, while, at day 6, ASC-EV act in synergy with the inflammatory cytokine, fostering its proproliferative action ( $+55 \%$ vs CTRL, $+12 \%$ vs TNF $\alpha$ alone) (Fig. 3c, right panel).

At last, the expression of Connexin 43 (Cx43), the most widely expressed connexin in the musculoskeletal system [53, 54], was investigated. Its levels are clearly down-modulated by TNF $\alpha$ (Fig. 3d, Supplementary Figure 2), especially in the long run (-60\% vs CTRL, Fig. 3d right panel). ASC-EV further reduced $\mathrm{Cx} 43$ expression at day 3 (-16\% vs TNF $\alpha$ alone, Fig. $3 \mathrm{~d}$ left panel) while the effect of ASC-CM is negligible.

\section{ASC-CM and ASC-EV present different factors of interest in the OA context}

Proteomic data analysis through OA-related keywords confirms that $\mathrm{CM}$ and $\mathrm{EV}$ protein profiles are distinct for all the considered processes (Fig. 4 and Supplementary Table 4). Of note, the analysis on chondroitin sulfate factors led to an important discrimination between $\mathrm{CM}$ and $\mathrm{EV}$, with more than $81.9 \%$ of variance explained by factors 1 and 2 (Fig. 4a, Supplementary Table 4). The most relevant differences were distinguishable in the 


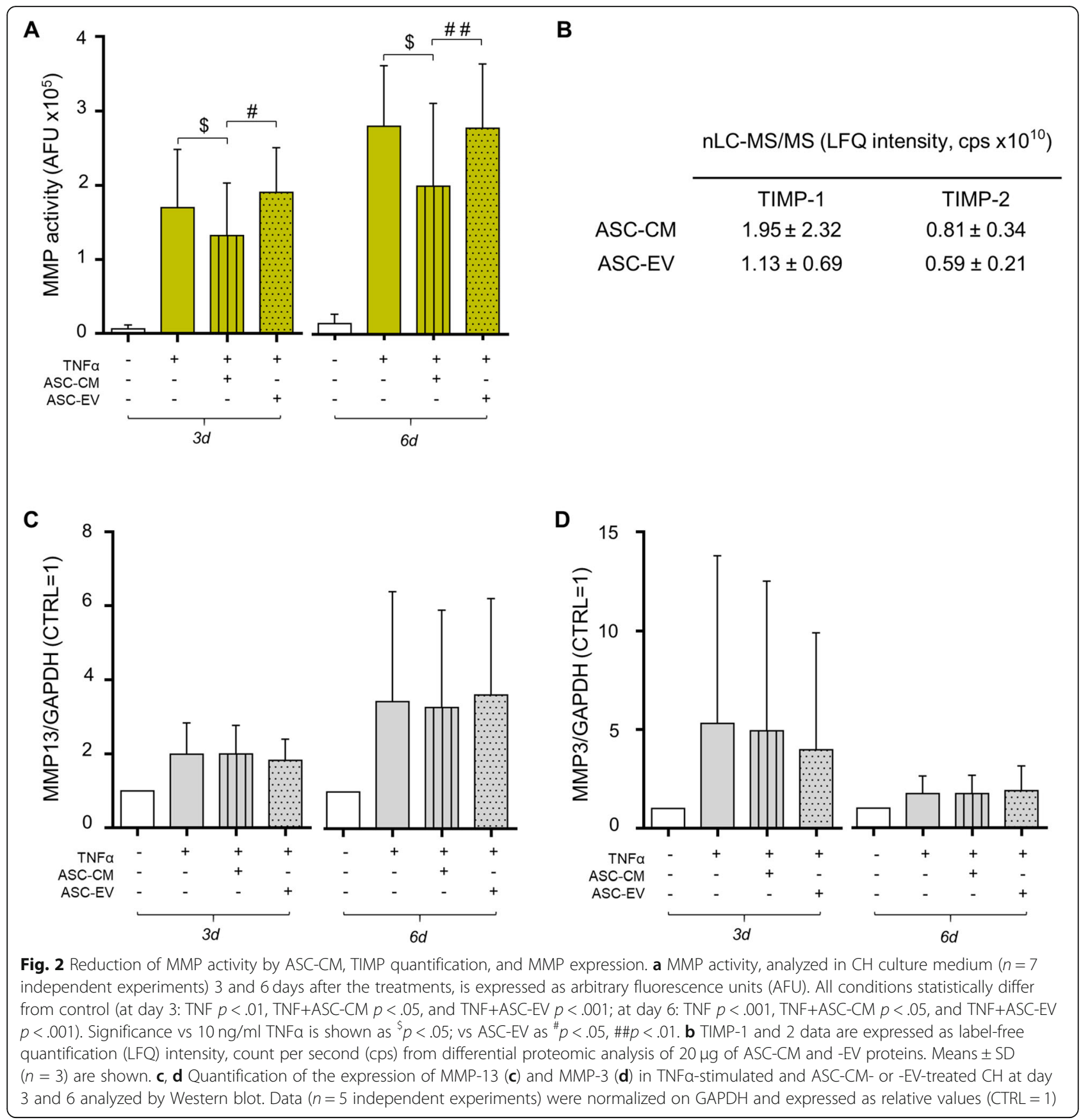

expression of Versican (greater than in ASC-EV) and Decorin and Biglycan (greater than in ASC-CM) (Fig. 4b and Supplementary Table 5). At last, a manual check for other proteins linked to OA allowed the identification of Bone Morphogenetic Protein 1, Dickkopf-related protein 3 , and 4 members of the ADAM (A Disintegrin and Metalloproteinase) family (in details ADAM10, ADAM12, ADAM17, and ADAM9) as more abundant in the CM samples (Supplementary Table 5). PCA on the factors associated to catabolism, metabolism, matrix, and inflammation allowed a distinction between $\mathrm{CM}$ and $\mathrm{EV}$, with a score always higher than $60 \%$ of variance explained by F1 and F2 (Fig. 4c-f and Supplementary Table 4).

\section{Discussion}

With the discovery that MSC engraftment and differentiation play a partial role in the success of cell therapy [55], over the years the scientific interest has shifted towards MSC-secreted factors. In the last decade, the 


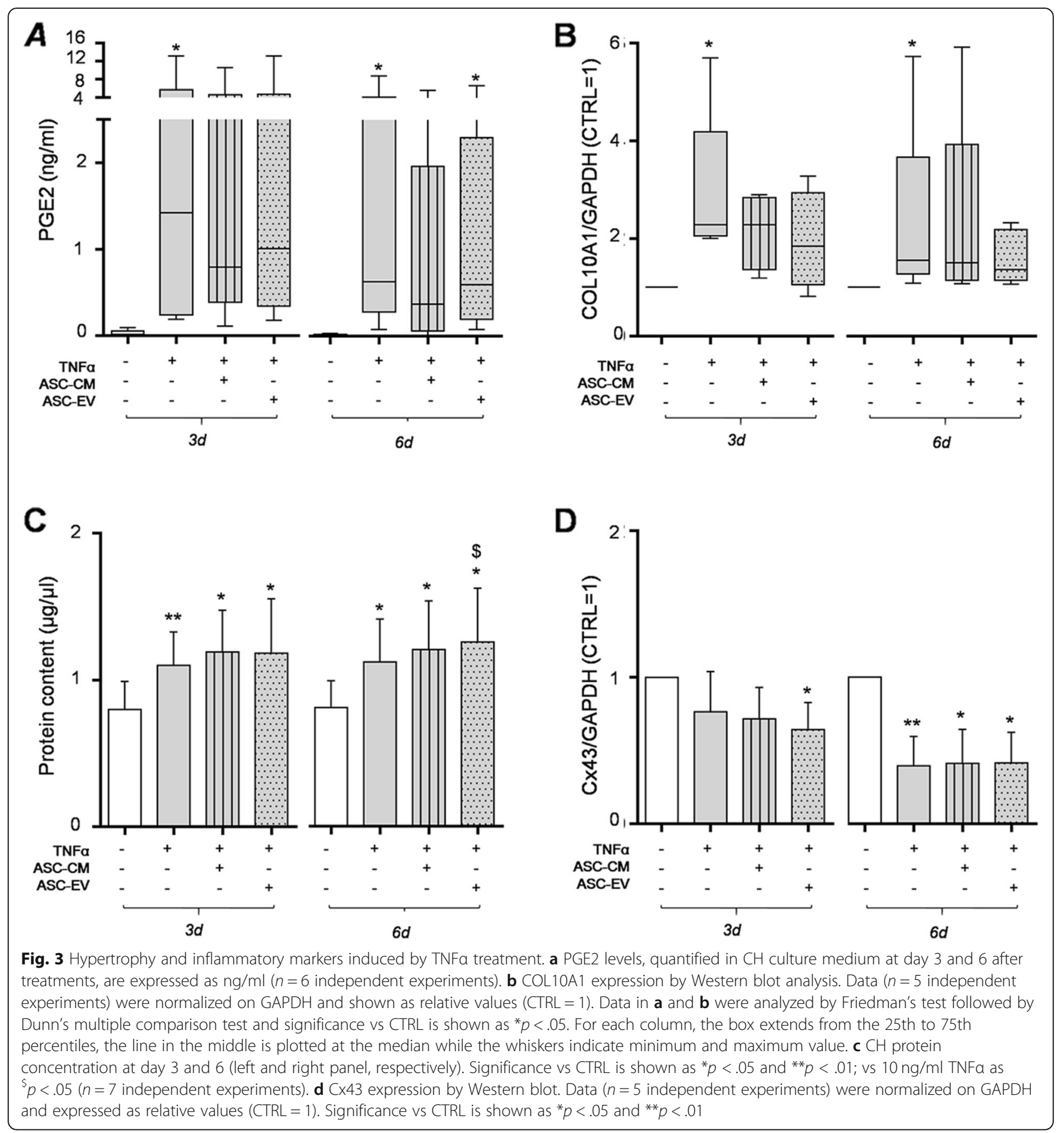

number of studies focused on the physical and functional characterization of MSC secretome has grown exponentially. Recently some cell-free products have reached the clinics in phase I and II trials [56] for diverse applications in which the beneficial action of the cells of origin was already well-documented [20, 21, 57]: MSC-CM in wound healing [58], alopecia [59, 60], bone regeneration [61], and multiple sclerosis [62], while MSC-EV in graft versus host disease [63], chronic kidney disease [64], type 1 diabetes, macular holes, and acute ischemic stroke (cited in [65]). Considering future clinical applications in the OA management, here, we compared the potential the potential of ASC whole secretome versus its EV component. Our treatment strategy follows what right now represents the gold standard for cell therapy, i.e., cell number-based dosage. This approach was already reported in literature for EV administration, both in vitro [66] and in vivo [67]. At first, the 

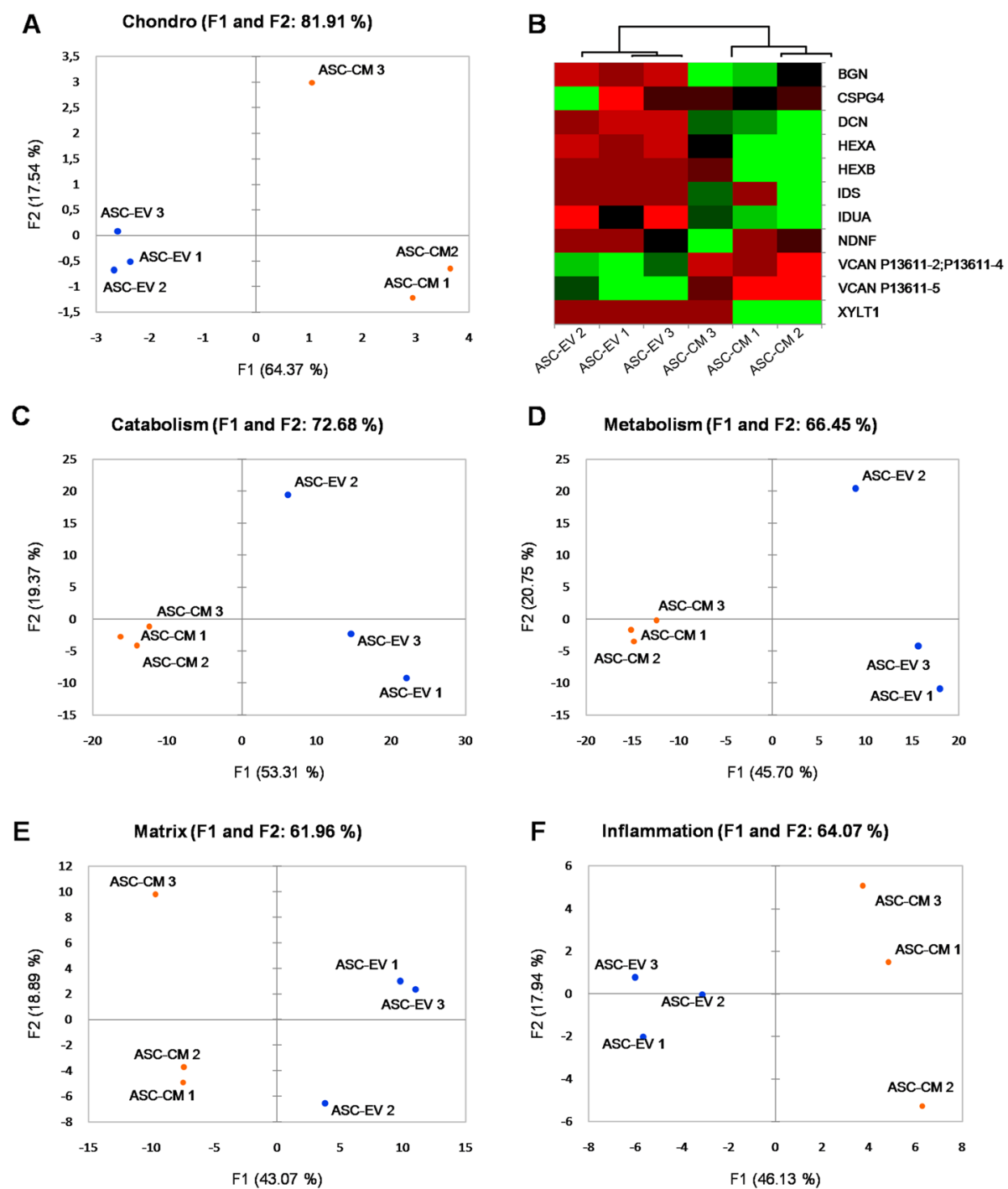

Fig. 4 PCA and heat map of chondroitin sulfate-related factors. PCA plots of the samples based on 10 chondroitin sulfate- (a), 56 inflammation(c), 425 catabolism- (d), 459 metabolism- (e), and 169 matrix- (f) mapped gene names. Color scale: red (down-represented) to green (uprepresented) through black. (b) Heat map for the chondroitin sulfate process-associated genes, constructed on the basis of protein abundance levels estimated by nLC-MS/MS in 3 ASC-CM (ASC-CM 1-3) and 3 ASC-EV (ASC-EV 1-3) samples. Principal component analysis (PCA) and heat maps were obtained using XLSTAT software. F1 and F2, factor 1 and 2

assumption that ASC-CM preparation allows a complete retention of the vesicular components $[27,68]$ has been validated. Then, we compared the two preparations focusing on size distribution, the presence of EV markers $[16,40]$ and particle concentration. Our data confirm that the EV isolation procedure through ultracentrifugation neither affected the quality of the particles nor enriched any subpopulation. Indeed, we confirmed a similar vesicular profile between ASC-CM and -EV in terms of dimensions, antigen expression, and granularity/complexity. Moreover, we give evidence of a 3 times higher vesicular yield in concentrated CM samples compared to $\mathrm{EV}$ ones, due to particle loss during the ultracentrifugation procedure [69-71]. Therefore, our in vitro data compare two preparations deriving from the same number of donor cells, with $\mathrm{CM}$ accounting for both soluble factors and a higher number of retained particles in comparison to ultracentrifuge-isolated EV. Conversely, our differential proteomic analysis considers the same protein amount for ASC-CM and -EV $(20 \mu \mathrm{g} /$ sample).

Both in vitro evidence and the differential analysis of the protein content between the two preparations suggest a higher therapeutic anti-OA potential of ASC-CM over ASC-EV. One of the most relevant differences was the lack of inhibition of MMP activity by ASC-EV, 
confirming our previous assumption that the blunting of MMP activity is a direct consequence of active TIMP in ASC secretome [27]. Indeed, these inhibitors are more represented in the complete secretome compared to the vesicular fraction. To our knowledge, it is the first time that the greater abundance of freely dissolved TIMP rather than EV-released ones is clearly defined. This aspect gains relevance in the light of developing MMP inhibitors as potential pharmacological tools in the management of a variety of diseases [72]. It also points out that for every pathology implying the aberrant activation of MMP [73, 74], the complete secretome, rather than the EV fraction alone, should be considered the more promising therapeutic strategy.

In addition, ASC-CM was more efficient in reducing the release of the inflammatory mediator PGE2 by TNF $\alpha$-stimulated $\mathrm{CH}$. This prostaglandin is known to exert multiple opposed functions based on its concentration. In our case, the down-modulation of PGE2 aimed at restoring its physiologic levels linked to a healthy $\mathrm{CH}$ phenotype. Indeed unstimulated chondrocytes release low amount of PGE2 (average release of about $20 \mathrm{pg} / \mathrm{ml}$ ) that are consistent with the concentration known to inhibit collagen cleavage and the expression of hypertrophy markers [75]. By contrast, TNFo raised PGE2 levels above the pro-anabolic concentration (average release of about $2.5 \mathrm{ng} / \mathrm{ml}$ ) and it is known that similar levels (from 1 to $1000 \mathrm{ng} / \mathrm{ml}$ ) exert a pro-catabolic and anti-anabolic effect on articular chondrocytes $[52,76]$. As follows, the reduction induced by ASC-CM appears beneficial. Vonk et al. [77] observed a more marked effect of CM compared to EV in reducing TNF $\alpha$ downstream effectors by $\mathrm{CH}$, in particular looking at cyclooxygenase-2 (COX2) expression. Indeed, TNF $\alpha$ treatment induces PGE2 release through the activation of COX2 transcription via NF-kB [78]. However, our data (Supplementary Figure 3) show the lack of a clearcut effect of ASC-CM on TNF $\alpha$-induced COX2 protein expression at 3 and 6 days, suggesting that the mechanisms underlying the blunting of PGE2 may act at a different level. Further investigations are currently ongoing to elucidate this aspect.

In our opinion the observed minor ASC-EV effects cannot be ascribed to the lack of internalization of $\mathrm{EV}$ into recipient cells. Indeed, administering $\mathrm{ASC}^{\mathrm{GFP}+}{ }_{-} \mathrm{EV}$ to stained $\mathrm{CH}$, a clear intracellular co-localization of the fluorescent signals was observed, suggesting an efficient EV uptake. ASC-EV incorporation has been already reported in other in vitro systems $[39,66]$ and future investigations will be necessary to disclose its underlying mechanisms (e.g., endocytosis and interaction of cell surface receptors [79]). Moreover, here, we show that EV modulate hypertrophy markers, contrasting TNF $\alpha$ action on COL10A1 expression to a similar-if not more marked-extent as ASC-CM. EV effect on chondrocytes seems less donor-dependent and more long-lasting compared to ASC-CM, suggesting that the mediator of COL10A1 reduction may be stored in EV and its beneficial action can be reduced by soluble factors. The regulation of COL10A1 gene expression during $\mathrm{CH}$ hypertrophic differentiation depends on multiple factors, including both transactivators and repressors (such as Runx2 and Sox9, respectively) and has not been fully elucidated yet [80]. However, in vitro evidences demonstrate that the overexpression of the miRNA hsa-miR148a decreases COL10A1 levels together with two other OA-related genes, MMP13 and ADAMTS5 [81]. Of note, the presence of hsa-miR-148a in EV derived from both naïve and IFNY-primed ASC has recently been demonstrated by Ragni et al., as shown in their Additional File 3 [82]. Moreover, here, we have identified Versican, a chondroitin sulfate proteoglycan, more abundant in EV. Interestingly, it plays important roles in chondrogenesis and in the retention of cartilage extracellular matrix (ECM) [83]. Even though EV reduced COL10A1 expression, suggesting a potential modulation of hypertrophy, no reduction on TNFo-mediated increased metabolism and proliferation was depicted. By contrast, we observed a slight increase in cell growth, previously reported also by Vonk et al. [77]. However, in their setting TNF $\alpha$ induced a reduction in chondrocyte proliferation that we have never observed in our in vitro model [27]. We ascribed the increase of chondrocyte proliferation by TNF $\alpha$ to the reduction of $\mathrm{Cx} 43$ expression, consistently with the fact that $\mathrm{Cx} 43 \mathrm{C}$-terminal domain (CTD) influences chondrocyte proliferation and phenotype maintenance [54]. Moreover, Cx43 reduction by TNF $\alpha$ has been shown in several cell types and plausible causes could be the activation of ubiquitinproteasome system [84] or the activation of JNK by TNF $\alpha$ [85]. Additionally, the cleavage of Cx43 CTD by MMP has been already documented [86] and further experiments will be performed with the aim of evaluating whether the reduced Cx43 signal depends either on the modulation of its protein expression or on a posttranslational mechanism.

Taken together, these results show that, given the same number of donor cells, ASC-CM is more efficient than ultracentrifuge-isolated EV. ASC-CM and ASC-EV present different protein composition not only in terms of quantity but also in terms of quality. Indeed, PCA shows specific differences in OA-related processes, spanning from ECM maintenance to inflammation. In details, ASC-CM appears to be more abundant in cartilage protective factors. Besides TIMP, we have identified other proteins involved in ECM organization and chondrogenesis. Among them, Biglycan (BGN) and Decorin (DCN), two small leucine-rich proteoglycans (SLRP), can bind 
different types of collagen and organize the fibrils. Moreover, they interact with TGF $\beta 1$ and control its signaling [87]. Also, BMP-1 plays an important role in collagen fibril organization. It cleaves C-propeptides of procollagens I, II, and III allowing the correct incorporation of monomers into growing fibrils [88]. Furthermore, it activates diverse TGF $\beta$ superfamily proteins that are fundamental for ECM formation and growth factor activity [89]. DKK-3 exerts protective roles in OA cartilage by interacting with TGF $\beta$ signaling, too [90]. Considering that, in the OA context, both collagen fibril organization and TGF $\beta$ signaling are affected $[91,92]$, the soluble factors present in ASC-CM could help in re-establishing a physiological condition. ASC-CM is enriched also in four ADAM, a group of enzymes involved in joint homeostasis. ADAM9 is involved in chondrogenesis [93], ADAM10 has a controversial functionality and its expression is increased in both developing and OA cartilage. Since its substrate in the articular district has not been identified yet, its implications in pathological conditions are still unclear [94]. In addition, ADAM12 seems to be associated to $\mathrm{OA}$ and chondrocyte maturation [94]. The presence in ASC-CM of TNF $\alpha$-activating pro-inflammatory ADAM17 could be dangerous; however, both its inhibitors TIMP-3 and CD9 [95] are present in the secretome as well [27], suggesting that this enzyme could be inactivated. This consideration highlights the complexity of secretome and the relevance of the balance between all the different factors.

\section{Conclusions}

In conclusion, our study suggests that soluble and EVassociated factors concur in a strongly synergistic manner to the anti-inflammatory, anti-hypertrophic, and anti-catabolic effect of ASC secretome. Even though we mainly investigated the differences in terms of protein content between the two cell products, we need to consider that they surely differ also in terms of nucleic acids such as miRNA and lipid composition. To date, the knowledge of the bioactive components eliciting a therapeutic action in different preclinical scenarios is still very limited, and their characterization in the perspective of a clinical translation is still ongoing. However, CM preparations, compared to EV isolated by ultracentrifugation, present several advantages, such as a higher vesicular yield and a lower manipulation, accounting for an easier compliance with good manufacturing practices (GMP) and a better scalability. Indeed, from a clinical point of view, CM production is cheaper and faster than EV isolation by the currently available, routinely used, techniques (e.g., ultracentrifugation and size exclusion chromatography). Moreover, CM yields a wider array of bioactive factors, soluble, freely dissolved proteins, nucleic acids, and lipids, with respect to the vesicular fraction alone [66]. In the future, more complex in vitro models, such as organoids or models considering the interaction with other articular cell types (e.g., synoviocytes and osteoblasts), should be set and additional preclinical investigations, focused on the optimization of $\mathrm{CM}$ production, will be performed in order to confirm the efficacy of ASC-CM in the OA context.

\section{Supplementary Information}

The online version contains supplementary material available at https://doi. org/10.1186/s13287-020-02035-5.

Additional file 1: Supplementary Figure 1. Representative images of EV incorporation by $\mathrm{CH}$. EV derived from $\mathrm{ASC}^{\mathrm{GFP}+}$ are indicated by green arrows, $\beta$-Tubulin was revealed with an Alexa Fluor ${ }^{\oplus} 568$ conjugated antibody (red) and nuclei were stained with DAPI (blue). The scale bars indicate $10 \mu \mathrm{m}$ and the orthogonal views referred to the EV encircled in yellow were obtained by Fiji software.

Additional file 2: Supplementary Figure 2. Representative Western Blot membrane for COL10A1, MMP-13, MMP-3, Cx43 and GAPDH.

Additional file 3: Supplementary Figure 3. (A) Quantification of the expression of COX2 (mAb \#12282, Cell Signaling Technology, Danvers, MA, USA) in TNFa-stimulated and ASC-CM or -EV treated CH at day 3 and 6 analyzed by Western Blot. Data ( $n=3$ independent experiments) were normalized on GAPDH and expressed as relative values $(C T R L=1)$. (B) Representative Western Blot membrane for COX2 and GAPDH.

Additional file 4: Supplementary Table 1. ASC features. Details of culture conditions (CTRL, Osteoinduction and Adipoinduction) and performed assays are reported. Supplementary Table 2. Functional enriched processes identified with STRING through OA-related keywords (Chondro-, Metabol-,Catabol-, Inflamm- and Matrix). GO: Gene ontology identifier. Supplementary Table 3.Quantification of OA-related factors in ASC-CM $(n=3)$ expressed as mean \pm SD. Details of the biological processes in which each factors is involved, according to Supplementary Table 2, are also provided. Supplementary Table 4. Principal Component Analysis (PCA) details by XLSTAT software. Number of factors analyzed for each OA-related keyword are reported in brackets.

Supplementary Table 5. nLC-MS/MS quantification of OA-related factors in ASC-CM and ASC-EV ( $n=3)$. Factors significantly different between CM and EV samples are in bold. Proteins more abundant in EV that in CM are highlighted in gray.

\section{Abbreviations}

ACl: Autologous chondrocyte implantation; ADAM: A disintegrin and metalloproteinase; AMPA: 4-Aminophenylmercuric acetate; ASC: Adiposederived stem/stromal cells; BGN: Biglycan; BMC: Bone marrow concentrate; BMI: Body mass index; CFSE: Carboxyfluorescein diacetate succinimidyl ester; $\mathrm{CH}$ : Articular chondrocytes; CM: Conditioned medium; COL10A1: Collagen type X; COX2: Cyclooxygenase-2; cps: Count per second; CTD: C-terminal domain; Cx43: Connexin 43; DCN: Decorin; DMOAD: Disease-modifying antiOA drugs; ECM: Extracellular matrix; EV: Extracellular vesicles; FASP: Filteraided sample preparation; GMP: Good manufacturing practices; LFQ: Labelfree quantification; MMP: Matrix metalloproteinases; MSC: Mesenchymal stem/stromal cells; NSAID: Non-steroidal anti-inflammatory drugs; NTA: Nanoparticle tracking analysis; OA: Osteoarthritis; PCA: Principal component analysis; PIC: Protease inhibitor cocktail; PRP: Platelet-rich plasma; SLRP: Small leucine-rich proteoglycans; STRING: Search Tool for the Retrieval of Interacting Genes/Proteins; TIMP: Tissue inhibitors of matrix metalloproteinases; WB: Western blotting

\section{Acknowledgements}

The authors would like to thank Dr. Giulio Alessandri (IRCCS Neurological Institute Carlo Besta, Milan) for providing the ASC ${ }^{\mathrm{GFP}+}$ cell line and Dr. Alessandro Bidossi (IRCCS Istituto Ortopedico Galeazzi, Milan) for the assistance with confocal imaging and analysis. 


\section{Authors' contributions}

C.G. and S.N. equally contributed to this work. Conceptualization, C.G., S.N. and A.T.B. Methodology, C.G., S.N., C.M., E.R., and A.A. Resources, C.G., S.N., C.M., E.R., A.A., and A.T.B. Data curation, C.G. and S.N. Writing-original draft preparation, C.G. and S.N. Writing-review and editing, C.M., E.R., A.A., and A.T.B. Supervision, A.T.B. Project administration, C.G., S.N., and A.T.B. Funding acquisition, A.T.B. All authors have read and agreed to the published version of the manuscript.

\section{Funding}

This research was funded by the Italian Ministry of Health, grant number RC L1027 and L1039, and by the University of Milan, Department of Biomedical Surgical and Dental Sciences, grant number RV_RIC_AT16RWEIBN_02 and RV_LIB16ABRIN_M. Funds for open-access publication fees were received from Istituto Ortopedico Galeazzi, Milan, Italy.

\section{Availability of data and materials}

The datasets used and/or analyzed during the current study are available from the corresponding author on reasonable request.

\section{Ethics approval and consent to participate}

Upon written informed consent and following the ethical principles of the Helsinki Declaration, human tissues were collected as waste material from the surgery room performed at IRCCS Istituto Ortopedico Galeazzi under Institutional Review Board approval (number 6/int/2018 approved by San Raffaele Hospital Ethics (ommittee).

\section{Consent for publication}

Not applicable.

\section{Competing interests}

The authors declare that they have no competing interests.

\section{Author details}

'Laboratorio di Applicazioni Biotecnologiche, IRCCS Istituto Ortopedico Galeazzi, Milan, Italy. ${ }^{2}$ Proteomics and Metabolomics Facility (ProMeFa), IRCCS San Raffaele Scientific Institute, Milan, Italy. ${ }^{3}$ Laboratorio di Biotecnologie Applicate all'Ortopedia, IRCCS Istituto Ortopedico Galeazzi, Milan, Italy. ${ }^{4}$ Department of Biomedical, Surgical and Dental Sciences, Università degli Studi di Milano, Milan, Italy.

Received: 9 September 2020 Accepted: 18 November 2020 Published online: 03 December 2020

\section{References}

1. Salmon JH, Rat AC, Sellam J, Michel M, Eschard JP, Guillemin F, et al. Economic impact of lower-limb osteoarthritis worldwide: a systematic review of cost-of-illness studies. Osteoarthr Cartil. 2016;24(9):1500-8.

2. Goldring SR, Goldring MB. Changes in the osteochondral unit during osteoarthritis: structure, function and cartilage-bone crosstalk. Nat Rev Rheumatol. 2016;12(11):632-44.

3. Berenbaum F. Osteoarthritis as an inflammatory disease (osteoarthritis is not osteoarthrosis!). Osteoarthr Cartil. 2013;21(1):16-21.

4. McAlindon TE, Bannuru RR, Sullivan MC, Arden NK, Berenbaum F, BiermaZeinstra SM, et al. OARSI guidelines for the non-surgical management of knee osteoarthritis. Osteoarthr Cartil. 2014;22(3):363-88.

5. Ragni E, Mangiavini L, Viganò M, Brini AT, Peretti GM, Banfi G, de Girolamo L. Management of Osteoarthritis During the COVID-19 Pandemic. Clin Pharmacol Ther. 2020;108(4):719-29. https://doi.org/10.1002/cpt.1910.

6. Huebner K, Frank RM, Getgood A. Ortho-biologics for osteoarthritis. Clin Sports Med. 2019;38(1):123-41.

7. Sherman BJ, Chahla J, Glowney J, Frank RM. The role of orthobiologics in the management of osteoarthritis and focal cartilage defects. Orthopedics. 2019;42(2):66-73.

8. Maumus M, Manferdini C, Toupet K, Peyrafitte JA, Ferreira R, Facchini A, et al. Adipose mesenchymal stem cells protect chondrocytes from degeneration associated with osteoarthritis. Stem Cell Res. 2013;11(2):83444.

9. Manferdini C, Maumus M, Gabusi E, Piacentini A, Filardo G, Peyrafitte JA, et al. Adipose-derived mesenchymal stem cells exert antiinflammatory effects on chondrocytes and synoviocytes from osteoarthritis patients through prostaglandin E2. Arthritis Rheum. 2013;65(5):1271-81.

10. Manferdini C, Maumus M, Gabusi E, Paolella F, Grassi F, Jorgensen C, et al. Lack of anti-inflammatory and anti-catabolic effects on basal inflamed osteoarthritic chondrocytes or synoviocytes by adipose stem cellconditioned medium. Osteoarthr Cartil. 2015;23(11):2045-57.

11. Lee KB, Hui JH, Song IC, Ardany L, Lee EH. Injectable mesenchymal stem cell therapy for large cartilage defects--a porcine model. Stem Cells. 2007; 25(11):2964-71.

12. Xie X, Wang Y, Zhao C, Guo S, Liu S, Jia W, et al. Comparative evaluation of MSCs from bone marrow and adipose tissue seeded in PRP-derived scaffold for cartilage regeneration. Biomaterials. 2012;33(29):7008-18.

13. Lim CT, Ren X, Afizah MH, Tarigan-Panjaitan S, Yang Z, Wu Y, Chian KS, Mikos AG, Hui JH. Repair of osteochondral defects with rehydrated freezedried oligo[poly(ethylene glycol) fumarate] hydrogels seeded with bone marrow mesenchymal stem cells in a porcine model. Tissue Eng Part A. 2013;19(15-16):1852-61. https://doi.org/10.1089/ten.TEA.2012.0621.

14. Fitzsimmons REB, Mazurek MS, Soos A, Simmons CA. Mesenchymal stromal/ stem cells in regenerative medicine and tissue engineering. Stem Cells Int 2018;2018:8031718.

15. van Niel G, D'Angelo G, Raposo G. Shedding light on the cell biology of extracellular vesicles. Nat Rev Mol Cell Biol. 2018;19(4):213-28.

16. Thery C, Witwer KW, Aikawa E, Alcaraz MJ, Anderson JD, Andriantsitohaina $R$, et al. Minimal information for studies of extracellular vesicles 2018 (MISE V2018): a position statement of the International Society for Extracellular Vesicles and update of the MISEV2014 guidelines. J Extracell Vesicles. 2018; 7(1):1535750.

17. Mancuso P, Raman S, Glynn A, Barry F, Murphy JM. Mesenchymal stem cell therapy for osteoarthritis: the critical role of the cell secretome. Front Bioeng Biotechnol. 2019;7:9.

18. D'Arrigo D, Roffi A, Cucchiarini M, Moretti M, Candrian C, Filardo G. Secretome and Extracellular Vesicles as New Biological Therapies for Knee Osteoarthritis: A Systematic Review. J Clin Med. 2019;8(11):1867. https://doi. org/10.3390/jcm8111867.

19. Chu DT, Nguyen Thi Phuong T, Tien NLB, Tran DK, Minh LB, Thanh W, Gia Anh P, Pham VH, Thi Nga V. Adipose Tissue Stem Cells for Therapy: An Update on the Progress of Isolation, Culture, Storage, and Clinical Application. J Clin Med. 2019;8(7):917. https://doi.org/10.3390/jcm8070917.

20. Squillaro T, Peluso G, Galderisi U. Clinical trials with mesenchymal stem cells: an update. Cell Transplant. 2016;25(5):829-48.

21. Gentile P, Casella D, Palma E, Calabrese C. Engineered Fat Graft Enhanced with Adipose-Derived Stromal Vascular Fraction Cells for Regenerative Medicine: Clinical, Histological and Instrumental Evaluation in Breast Reconstruction. J Clin Med. 2019;8(4):504. https://doi.org/10.3390/ jcm8040504.

22. Sánchez-Guijo F, García-Arranz M, López-Parra M, Monedero P, MataMartínez C, Santos A, et al. Adipose-derived mesenchymal stromal cells for the treatment of patients with severe SARS-CoV-2 pneumonia requiring mechanical ventilation. A proof of concept study. EClinicalMedicine. 2020; 25:100454.

23. Gentile P, Sterodimas A. Adipose stem cells (ASCs) and stromal vascular fraction (SVF) as a potential therapy in combating (COVID-19)-disease. Aging Dis. 11: Copyright: @ 2020 Gentile et al.; 2020. p. 465-469.

24. Niada S, Giannasi C, Gualerzi A, Banfi G, Brini AT. Differential proteomic analysis predicts appropriate applications for the secretome of adiposederived mesenchymal stem/stromal cells and dermal fibroblasts. Stem Cells Int. 2018;2018:7309031.

25. Gualerzi A, Niada S, Giannasi C, Picciolini S, Morasso C, Vanna R, et al. Raman spectroscopy uncovers biochemical tissue-related features of extracellular vesicles from mesenchymal stromal cells. Sci Rep. 2017;7(1):9820.

26. Gualerzi A, Kooijmans SAA, Niada S, Picciolini S, Brini AT, Camussi G, et al. Raman spectroscopy as a quick tool to assess purity of extracellular vesicle preparations and predict their functionality. J Extracell Vesicles. 2019;8(1): 1568780.

27. Niada S, Giannasi C, Gomarasca M, Stanco D, Casati S, Brini AT. Adiposederived stromal cell secretome reduces TNFalpha-induced hypertrophy and catabolic markers in primary human articular chondrocytes. Stem Cell Res. 2019;38:101463.

28. Laganà M, Arrigoni C, Lopa S, Sansone V, Zagra L, Moretti M, et al. Characterization of articular chondrocytes isolated from 211 osteoarthritic patients. Cell Tissue Bank. 2014;15(1):59-66. 
29. de Girolamo L, Lopa S, Arrigoni E, Sartori MF, Baruffaldi Preis FW, Brini AT. Human adipose-derived stem cells isolated from young and elderly women: their differentiation potential and scaffold interaction during in vitro osteoblastic differentiation. Cytotherapy. 2009;11(6):793-803.

30. Jakob M, Démarteau O, Schäfer D, Stumm M, Heberer M, Martin I. Enzymatic digestion of adult human articular cartilage yields a small fraction of the total available cells. Connect Tissue Res. 2003;44(3-4): 173-80.

31. Giannasi C, Pagni G, Polenghi C, Niada S, Manfredi B, Brini AT, et al. Impact of dental implant surface modifications on adhesion and proliferation of primary human gingival keratinocytes and progenitor cells. Int J Periodontics Restorative Dent. 2018;38(1):127-35.

32. Brini AT, Cocce V, Ferreira LM, Giannasi C, Cossellu G, Gianni AB, et al. Cellmediated drug delivery by gingival interdental papilla mesenchymal stromal cells (GinPa-MSCs) loaded with paclitaxel. Expert Opin Drug Deliv. 2016;13(6):789-98.

33. Niada S, Giannasi C, Ferreira LM, Milani A, Arrigoni E, Brini AT. 17betaestradiol differently affects osteogenic differentiation of mesenchymal stem/ stromal cells from adipose tissue and bone marrow. Differentiation. 2016; 92(5):291-7.

34. Niada S, Ferreira LM, Arrigoni E, Addis A, Campagnol M, Broccaioli E, et al. Porcine adipose-derived stem cells from buccal fat pad and subcutaneous adipose tissue for future preclinical studies in oral surgery. Stem Cell Res Ther. 2013;4(6):148.

35. Petrenko Y, Vackova I, Kekulova K, Chudickova M, Koci Z, Turnovcova K, et al. A comparative analysis of multipotent mesenchymal stromal cells derived from different sources, with a focus on neuroregenerative potential. Sci Rep. 2020;10(1):4290.

36. Brini AT, Amodeo G, Ferreira LM, Milani A, Niada S, Moschetti G, et al. Therapeutic effect of human adipose-derived stem cells and their secretome in experimental diabetic pain. Sci Rep. 2017;7(1):9904.

37. Pergoli L, Cantone L, Favero C, Angelici L, lodice S, Pinatel E, et al. Extracellular vesicle-packaged miRNA release after short-term exposure to particulate matter is associated with increased coagulation. Part Fibre Toxicol. 2017;14(1):32.

38. Rezaie J, Nejati V, Khaksar M, Oryan A, Aghamohamadzadeh N, Shariatzadeh MA, et al. Diabetic sera disrupted the normal exosome signaling pathway in human mesenchymal stem cells in vitro. Cell Tissue Res. 2018;374(3):555-65.

39. Ragni E, Perucca Orfei C, De Luca P, Lugano G, Vigano M, Colombini A, et al. Interaction with hyaluronan matrix and miRNA cargo as contributors for in vitro potential of mesenchymal stem cell-derived extracellular vesicles in a model of human osteoarthritic synoviocytes. Stem Cell Res Ther. 2019; 10(1):109.

40. Lötvall J, Hill AF, Hochberg F, Buzás El, Di Vizio D, Gardiner C, et al. Minimal experimental requirements for definition of extracellular vesicles and their functions: a position statement from the International Society for Extracellular Vesicles. J Extracell Vesicles. 2014;3:26913.

41. Cocce V, Balducci L, Falchetti ML, Pascucci L, Ciusani E, Brini AT, et al. Fluorescent immortalized human adipose derived stromal cells (hASCs-TS/ GFP+) for studying cell drug delivery mediated by microvesicles. Anti Cancer Agents Med Chem. 2017;17(11):1578-85.

42. Caron MM, Emans PJ, Coolsen MM, Voss L, Surtel DA, Cremers A, et al. Redifferentiation of dedifferentiated human articular chondrocytes: comparison of 2D and 3D cultures. Osteoarthr Cartil. 2012;20(10):1170-8.

43. Goldring MB. Human chondrocyte cultures as models of cartilage-specific gene regulation. Methods Mol Med. 2005;107:69-95.

44. Westacott Cl, Barakat AF, Wood L, Perry MJ, Neison P, Bisbinas I, et al. Tumor necrosis factor alpha can contribute to focal loss of cartilage in osteoarthritis. Osteoarthr Cartil. 2000:8(3):213-21.

45. Wisniewski JR, Zougman A, Nagaraj N, Mann M. Universal sample preparation method for proteome analysis. Nat Methods. 2009:6(5):359-62.

46. Cox J, Neuhauser N, Michalski A, Scheltema RA, Olsen JV, Mann M. Andromeda: a peptide search engine integrated into the MaxQuant environment. J Proteome Res. 2011;10(4):1794-805.

47. Giannasi C, Niada S, Farronato D, Lombardi G, Manfredi B, Farronato G, et al. Nitrogen containing bisphosphonates impair the release of bone homeostasis mediators and matrix production by human primary preosteoblasts. Int J Med Sci. 2019;16(1):23-32.
48. Singh P, Marcu KB, Goldring MB, Otero M. Phenotypic instability of chondrocytes in osteoarthritis: on a path to hypertrophy. Ann N Y Acad Sci. 2019;1442(1):17-34. https://doi.org/10.1111/nyas.13930.

49. Wang M, Sampson ER, Jin H, Li J, Ke QH, Im HJ, et al. MMP13 is a critica target gene during the progression of osteoarthritis. Arthritis Res Ther. 2013; 15(1):R5.

50. van der Kraan PM, van den Berg WB. Chondrocyte hypertrophy and osteoarthritis: role in initiation and progression of cartilage degeneration? Osteoarthr Cartil. 2012;20(3):223-32

51. Li TF, Zuscik MJ, lonescu AM, Zhang X, Rosier RN, Schwarz EM, et al. PGE2 inhibits chondrocyte differentiation through PKA and PKC signaling. Exp Cell Res. 2004;300(1):159-69.

52. Attur M, Al-Mussawir HE, Patel J, Kitay A, Dave M, Palmer G, et al. Prostaglandin E2 exerts catabolic effects in osteoarthritis cartilage: evidence for signaling via the EP4 receptor. J Immunol. 2008;181(7):5082-8.

53. Donahue HJ, Qu RW, Genetos DC. Joint diseases: from connexins to gap junctions. Nat Rev Rheumatol. 2017;14(1):42-51.

54. Gago-Fuentes R, Bechberger JF, Varela-Eirin M, Varela-Vazquez A, Acea B, Fonseca $\mathrm{E}$, et al. The $\mathrm{C}$-terminal domain of connexin43 modulates cartilage structure via chondrocyte phenotypic changes. Oncotarget. 2016;7(45): 73055-67.

55. Caplan Al. Mesenchymal stem cells: time to change the name! Stem Cells Transl Med. 2017:6(6):1445-51.

56. Bogatcheva NV, Coleman ME. Conditioned medium of mesenchymal stromal cells: a new class of therapeutics. Biochemistry (Mosc). 2019;84(11): 1375-89.

57. Gentile P, Garcovich S. Advances in Regenerative Stem Cell Therapy in Androgenic Alopecia and Hair Loss: Wnt pathway, Growth-Factor, and Mesenchymal Stem Cell Signaling Impact Analysis on Cell Growth and Hair Follicle Development. Cells. 2019;8(5):466. https://doi.org/10.3390/ cells8050466.

58. Zhou BR, Xu Y, Guo SL, Wang Y, Zhu F, Permatasari F, et al. The effect of conditioned media of adipose-derived stem cells on wound healing after ablative fractional carbon dioxide laser resurfacing. Biomed Res Int. 2013; 2013:519126.

59. Fukuoka H, Narita K, Suga H. Hair regeneration therapy: application of adipose-derived stem cells. Curr Stem Cell Res Ther. 2017;12(7):531-4.

60. Shin $\mathrm{H}$, Won $\mathrm{CH}$, Chung WK, Park BS. Up-to-date clinical trials of hair regeneration using conditioned media of adipose-derived stem cells in male and female pattern hair loss. Curr Stem Cell Res Ther. 2017;12(7): 524-30.

61. Katagiri W, Watanabe J, Toyama N, Osugi M, Sakaguchi K, Hibi H. Clinical study of bone regeneration by conditioned medium from mesenchymal stem cells after maxillary sinus floor elevation. Implant Dent. 2017;26(4):607-12.

62. Dahbour S, Jamali F, Alhattab D, Al-Radaideh A, Ababneh O, Al-Ryalat $\mathrm{N}$, et al. Mesenchymal stem cells and conditioned media in the treatment of multiple sclerosis patients: clinical, ophthalmological and radiological assessments of safety and efficacy. CNS Neurosci Ther. 2017;23(11):866-74

63. Kordelas L, Rebmann V, Ludwig AK, Radtke S, Ruesing J, Doeppner TR, et al. MSC-derived exosomes: a novel tool to treat therapy-refractory graft-versushost disease. Leukemia. 2014;28:970-3.

64. Nassar W, El-Ansary M, Sabry D, Mostafa MA, Fayad T, Kotb E, et al. Umbilical cord mesenchymal stem cells derived extracellular vesicles can safely ameliorate the progression of chronic kidney diseases. Biomater Res. 2016; 20:21.

65. Fujita Y, Kadota T, Araya J, Ochiya T, Kuwano K. Clinical Application of Mesenchymal Stem Cell-Derived Extracellular Vesicle-Based Therapeutics for Inflammatory Lung Diseases. J Clin Med. 2018;7(10):355. https://doi.org/10. 3390/jcm7100355.

66. Mitchell R, Mellows B, Sheard J, Antonioli M, Kretz O, Chambers D, et al. Secretome of adipose-derived mesenchymal stem cells promotes skeletal muscle regeneration through synergistic action of extracellular vesicle cargo and soluble proteins. Stem Cell Res Ther. 2019;10(1):116.

67. Drommelschmidt K, Serdar M, Bendix I, Herz J, Bertling F, Prager S, et al. Mesenchymal stem cell-derived extracellular vesicles ameliorate inflammation-induced preterm brain injury. Brain Behav Immun. 2017:60: 220-32. 
68. Vergauwen G, Dhondt B, Van Deun J, De Smedt E, Berx G, Timmerman E, et al. Confounding factors of ultrafiltration and protein analysis in extracellular vesicle research. Sci Rep. 2017;7(1):2704.

69. Brennan K, Martin K, FitzGerald SP, O'Sullivan J, Wu Y, Blanco A, Richardson C, Mc Gee MM. A comparison of methods for the isolation and separation of extracellular vesicles from protein and lipid particles in human serum. Sci Rep. 2020;10(1):1039. https://doi.org/10.1038/s41598-020-57497-7.

70. Takov K, Yellon DM, Davidson SM. Comparison of small extracellular vesicles isolated from plasma by ultracentrifugation or size-exclusion chromatography: yield, purity and functional potential. J Extracell Vesicles. 2019;8(1):1560809.

71. Tang $Y T$, Huang $Y Y$, Zheng $L$, Qin SH, Xu XP, An TX, et al. Comparison of isolation methods of exosomes and exosomal RNA from cell culture medium and serum. Int J Mol Med. 2017;40(3):834-44.

72. Liu J, Khalil RA. Matrix metalloproteinase inhibitors as investigational and therapeutic tools in unrestrained tissue remodeling and pathological disorders. Prog Mol Biol Transl Sci. 2017;148:355-420.

73. Hu J, Van den Steen PE, Sang QX, Opdenakker G. Matrix metalloproteinase inhibitors as therapy for inflammatory and vascular diseases. Nat Rev Drug Discov. 2007;6(6):480-98.

74. Kawasaki $Y, X u$ ZZ, Wang X, Park JY, Zhuang ZY, Tan PH, et al. Distinct roles of matrix metalloproteases in the early- and late-phase development of neuropathic pain. Nat Med. 2008;14(3):331-6.

75. Tchetina EV, Di Battista JA, Zukor DJ, Antoniou J, Poole AR. Prostaglandin PGE2 at very low concentrations suppresses collagen cleavage in cultured human osteoarthritic articular cartilage: this involves a decrease in expression of proinflammatory genes, collagenases and COL10A1, a gene linked to chondrocyte hypertrophy. Arthritis Res Ther. 2007;9(4):R75.

76. Li X, Ellman M, Muddasani P, Wang JH, Cs-Szabo G, van Wijnen AJ, et al. Prostaglandin E2 and its cognate EP receptors control human adult articular cartilage homeostasis and are linked to the pathophysiology of osteoarthritis. Arthritis Rheum. 2009:60(2):513-23.

77. Vonk LA, van Dooremalen SFJ, Liv N, Klumperman J, Coffer PJ, Saris DBF, et al. Mesenchymal stromal/stem cell-derived extracellular vesicles promote human cartilage regeneration in vitro. Theranostics. 2018;8(4):906-20.

78. Roman-Blas JA, Jimenez SA. NF-kappaB as a potential therapeutic target in osteoarthritis and rheumatoid arthritis. Osteoarthr Cartil. 2006;14(9):839-48.

79. Gomzikova M, Kletukhina S, Kurbangaleeva S, Rizvanov A. Evaluation of cytochalasin B-induced membrane vesicles fusion specificity with target cells. Biomed Res Int. 2018;2018:7053623.

80. Gu J, Lu Y, Li F, Qiao L, Wang Q, Li N, et al. Identification and characterization of the novel Col10a1 regulatory mechanism during chondrocyte hypertrophic differentiation. Cell Death Dis. 2014;5(10):e1469.

81. Vonk LA, Kragten AH, Dhert WJ, Saris DB, Creemers LB. Overexpression of hsa-miR-148a promotes cartilage production and inhibits cartilage degradation by osteoarthritic chondrocytes. Osteoarthr Cartil. 2014;22(1): 145-53.

82. Ragni E, Perucca Orfei C, De Luca P, Mondadori C, Viganò M, Colombini A, et al. Inflammatory priming enhances mesenchymal stromal cell secretome potential as a clinical product for regenerative medicine approaches through secreted factors and EV-miRNAs: the example of joint disease. Stem Cell Res Ther. 2020;11(1):165.

83. Choocheep K, Hatano S, Takagi H, Watanabe H, Kimata K, Kongtawelert P. Versican facilitates chondrocyte differentiation and regulates joint morphogenesis. J Biol Chem. 2010;285(27):21114-25.

84. Zhang FF, Morioka N, Kitamura T, Hisaoka-Nakashima K, Nakata Y. Proinflammatory cytokines downregulate connexin 43-gap junctions via the ubiquitin-proteasome system in rat spinal astrocytes. Biochem Biophys Res Commun. 2015:464(4):1202-8.

85. Kimura K, Orita T, Morishige N, Nishida T, Sonoda KH. Role of the JNK signaling pathway in downregulation of connexin43 by TNF-alpha in human corneal fibroblasts. Curr Eye Res. 2013;38(9):926-32.

86. De Bock M, Wang N, Decrock E, Bultynck G, Leybaert L. Intracellular cleavage of the Cx43 C-terminal domain by matrix-metalloproteases: a novel contributor to inflammation? Mediat Inflamm. 2015;2015:257471.

87. Embree MC, Kilts TM, Ono M, Inkson CA, Syed-Picard F, Karsdal MA, et al. Biglycan and fibromodulin have essential roles in regulating chondrogenesis and extracellular matrix turnover in temporomandibular joint osteoarthritis. Am J Pathol. 2010;176(2):812-26.
88. Kessler E, Takahara K, Biniaminov L, Brusel M, Greenspan DS. Bone morphogenetic protein-1: the type I procollagen C-proteinase. Science. 1996;271(5247):360-2.

89. Hopkins DR, Keles S, Greenspan DS. The bone morphogenetic protein 1/ Tolloid-like metalloproteinases. Matrix Biol. 2007;26(7):508-23.

90. Snelling SJ, Davidson RK, Swingler TE, Le LT, Barter MJ, Culley KL, et al. Dickkopf-3 is upregulated in osteoarthritis and has a chondroprotective role. Osteoarthr Cartil. 2016;24(5):883-91.

91. Wen CY, Wu CB, Tang B, Wang T, Yan CH, Lu WW, et al. Collagen fibril stiffening in osteoarthritic cartilage of human beings revealed by atomic force microscopy. Osteoarthr Cartil. 2012;20(8):916-22.

92. Shen J, Li S, Chen D. TGF- $\beta$ signaling and the development of osteoarthritis. Bone Res. 2014;2:14002-09. https://doi.org/10.1038/boneres.2014.2.

93. Djouad F, Delorme B, Maurice M, Bony C, Apparailly F, Louis-Plence P, et al. Microenvironmental changes during differentiation of mesenchymal stem cells towards chondrocytes. Arthritis Res Ther. 2007;9(2):R33.

94. Yang CY, Chanalaris A, Troeberg L. ADAMTS and ADAM metalloproteinases in osteoarthritis - looking beyond the 'usual suspects'. Osteoarthr Cartil. 2017;25(7):1000-9.

95. Scheller J, Chalaris A, Garbers C, Rose-John S. ADAM17: a molecular switch to control inflammation and tissue regeneration. Trends Immunol. 2011; 32(8):380-7.

\section{Publisher's Note}

Springer Nature remains neutral with regard to jurisdictional claims in published maps and institutional affiliations.
Ready to submit your research? Choose BMC and benefit from:

- fast, convenient online submission

- thorough peer review by experienced researchers in your field

- rapid publication on acceptance

- support for research data, including large and complex data types

- gold Open Access which fosters wider collaboration and increased citations

- maximum visibility for your research: over $100 \mathrm{M}$ website views per year

At BMC, research is always in progress.

Learn more biomedcentral.com/submissions 